\title{
EDUCATING FOR A SUSTAINABILITY MINDSET
}

KENT D. FAIRFIELD

Silberman College of Business

Institute for Sustainable Enterprise

Fairleigh Dickinson University

Teaneck, New Jersey, U.S.A.

kent@fdu.edu

Abstract. Organizations around the world have become increasingly concerned about managing for sustainability, yet undergraduate education about sustainability often presents the challenge of dealing with students equipped with a modest understanding of business and sustainability issues and whose awareness is sometimes politicized. Traditional-aged students are at a stage where they derive their own worldview on many subjects, including their place in a broader world. As such, equipping them to be useful professionals for the future, or even to specialize in sustainabilityoriented careers, requires raising their awareness of the global situation in environmental, societal, political, and business terms. A curriculum must get them acquainted with what is needed for the world to reach a more fruitful future as well as with strategies the business sector can pursue to accomplish such an objective. More importantly, however, it should elicit a new worldview about sustainability and, even more profoundly, a deeply felt mindset embracing one's purpose, feelings, and identity. This article thus proposes a means by which students can embody the ability and confidence to make an appreciable impact toward a sustainable planet.

Keywords: teaching sustainability; sustainability mindset; sustainability worldview; identity; Principles for Responsible Management Education; PRME; United Nations

The importance of issues in sustainability has grown far beyond early concerns about automobile gas mileage, plastic shopping bag use, and air pollution control. The majority of the public worldwide has come 
to believe in the severity of global climate change. Widespread income inequality has continued to rise due to growing prosperity among the world's affluent while over 800 million remain mired in chronic poverty. Desertification and a rising sea level have eroded the ability of a massive segment of the population to scratch out a living even on the level of subsistence. As a result, millions suffer from ill health, despair, early mortality, and civil unrest.

Universities hoping to form undergraduates today to become productive professionals tomorrow are thus obliged to arm them with at least a basic competence in dealing with sustainability issues. This article will discuss my attempt to accomplish this, beginning with raising the awareness of students about the state of the world. It will then suggest some of the things that need to be done to move the planet toward a more sustainable condition, followed by a review of what an educated business graduate needs to learn about what businesses should do, what is already being done in many quarters, and what the business sector's potential for powerful impact is in the future. Finally, the article describes a sustainability worldview and, even more powerful, a sustainability mindset that students need if they are to become serious critics, advocates, and executives in improving the sustainability of the world. I will include steps that I have taken to move toward these goals and indicate where I wish to go further in the future.

\section{UNDERSTANDING THE STATE OF THE WORLD}

A starting point for educating about sustainability is to ensure that all students have at least a modicum of knowledge about the world today. One challenge I have thus encountered is that entering students vary widely in this regard: some come from highly educated families where world affairs make up a steady diet of conversation while other households have been preoccupied merely with keeping food on the table. A sizable cohort comes from overseas to study, or are children of immigrants, who have personal knowledge of two or more countries; some of them are still painfully aware of the world poverty, water shortages, illiteracy, and devastating weather events that they left behind. Still others have grown up with views that politicize issues like climate change, environmental regulation, and care for refugees or the poor.

We use several sources to acquaint students with concerns for the environment and society. One source of global challenge comes from the United Nations-in 2015, 193 member countries agreed to an ambitious list of 17 Sustainable Development Goals (SDGs) with 169 targets for 
2030 and which cover a range of issues. This includes such things as No Poverty, Good Health and Well-Being, Quality Education, and Climate Action (see complete list in Figure 1). Several of these Goals, such as Good Health and Well-Being, Reduced Inequalities, Gender Equality, and Clean Water and Sanitation, depend squarely on the behavior of businesses, especially those operating in developing countries.
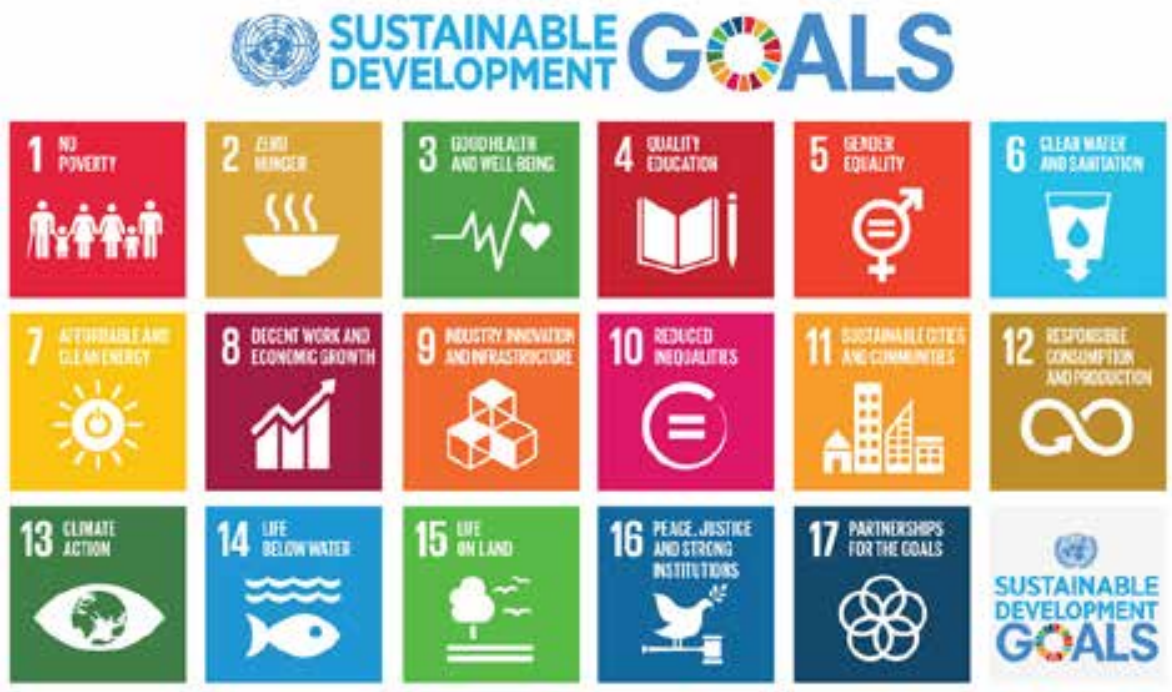

Figure 1: UN Sustainable Development Goals (United Nations, 2017; see http://www. un.org/sustainabledevelopment/news/communications-material/)

As these Goals arose from the United Nations, they are now an explicit part of the expectations for all those business schools that signed on for the UN's Principles for Responsible Management Education (PRME). Our college of business, however, has not only dedicated itself to infusing the business curriculum with these SDGs but has also helped promote their introduction to our sister colleges at the university, including those focused on liberal arts and sciences, engineering, healthcare, and hospitality. Students in all those areas will deepen their education by learning how the SDGs apply to human activity in their disciplines.

Another source of insight and encouragement for businesses striving to become more sustainable originates with the Future-Fit Foundation in its free, non-copyrighted electronic book. The Future-fit business benchmark (2016) identifies sixteen Global Challenges that threaten the future of businesses and the planet in our resource-constrained, environmentally 
endangered world. These include climate destabilization, health crisis, governance failure, and social instability (see Table 1 for the complete list).

1. Climate destabilization

2. Ocean acidification

3. Biodiversity crisis

4. Ecosystem degradation

5. Access to mined materials

6. Access to renewable materials

7. Energy crisis

8. Fresh water crisis

9. Food crisis

10. Health crisis

11. Infrastructure crisis

12. Governance failure

13. Financial inequality

14. Education crisis

15. Social instability

16. Erosion of trust

Table 1: Global Challenges According to Future-Fit Business Benchmark (2016)

\section{WHAT NEEDS TO BE DONE}

A traditional way of framing sustainability for many years has been through the Triple Bottom Line and the importance of society, environment, and economy, or "people, planet and profit" (Elkington, 1998). More recently, however, scholars have come to regard this approach as suggesting possible competing priorities that only sometimes overlap toward the same pursuits (Figure 2a). A more satisfactory conceptualization, therefore, is to acknowledge instead that any person or company resides inescapably within society, which itself occupies space in the natural world. Indeed, any organization derives inputs from society, whether employees, investors, manufactured components, or infrastructure. Society also has a similar impact on the natural environment, which in turn provides a range of inputs such as clean air, tillable land, mineable materials, biodiverse animal life, water, and the like. Thus, even though it is natural to ignore such dependence on the environment, this framing is more complete, and it reminds us that we live in a nested existence, unable to separate ourselves from influences outside our door (Barbier, 1987; see Figure 2). 


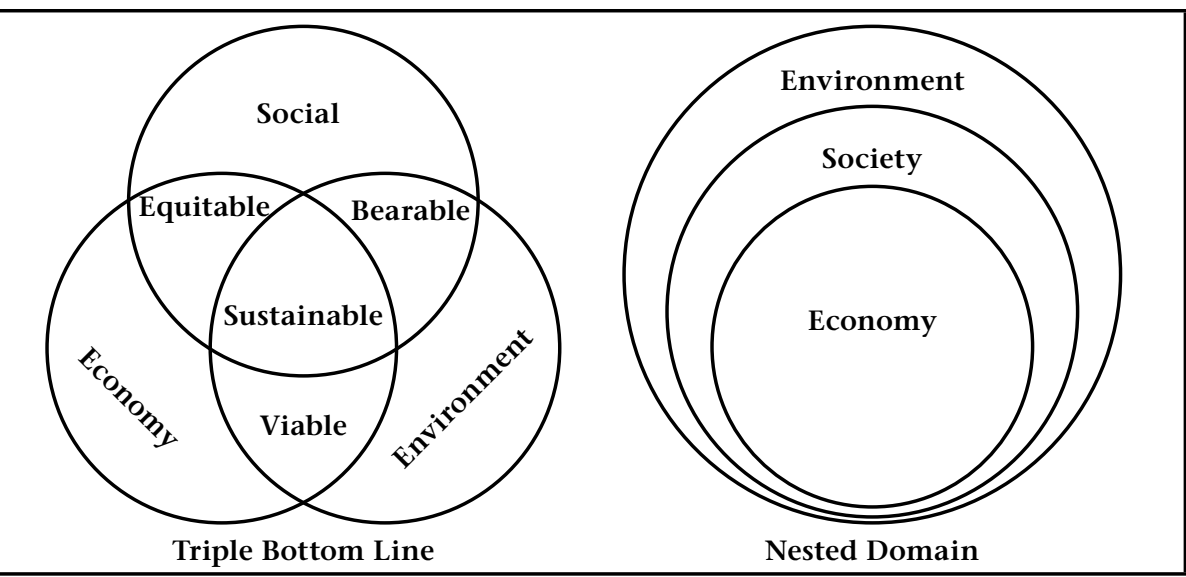

Figure 2: Dimensions of Sustainability Concepts (Elkington, 1998; Future-Fit Foundation, 2016: 12)

As such, one important element that needs to be part of a discussion about sustainability is the extent to which one should strive to improve. Companies that make a well-intended effort to reduce carbon emissions, raise wages for the lowest earners, or cut back toxic chemicals in their products may think about dire predictions of global decline and wonder: "Is it enough to improve our performance only somewhat? Compared to what? Simply to slow down but not suspend worldwide deterioration? Or do we need to take steps that bring about the absolute, long-term prospering of the world? How much is enough?"

John Ehrenfeld, professor emeritus of engineering from MIT, offers his answer. He asserts that almost all business and personal efforts today that purport to increase sustainability are really concerned only with reducing un-sustainability (Ehrenfeld \& Hoffman, 2013). While it does somewhat help when vehicle fleets consume less fossil fuel, or power plants use natural gas instead of coal, or world poverty is cut in half, Ehrenfeld's ultimate goal is for sustainability to be "the possibility that human and other life will flourish on the planet forever" (Ehrenfeld, 2009: 1).

Three words stand out in this simple statement. First, Ehrenfeld speaks not just of improving life on earth but of flourishing. This is a powerful word whose force comes through in the quip attributed by Peter Senge to Michael Braungart: "If someone asked you how your marriage was and you said, 'it's sustainable,' this would not be a good thing" (Laszlo \& Brown, 2014: ix). Clearly, flourishing is a far higher standard. The second unexpected element is when Ehrenfeld's definition includes not just humans but all forms of life. This differs from most cultures in 
the world which focus on humans as the dominant species and the only one that ultimately matters, not plants and other animal life.

The third powerful idea is when this definition speaks of sustainability not "in the future" or "in the next century" but as forever. The authors of the Future-fit business benchmark design their approach (to be explicated more thoroughly in Part 2 of their e-book) to pursue just such a standard. They are among those who discourage the formulation of the Triple Bottom Line insofar as it implies that part of business activity is separate from society and the environment. For them, today's global challenges, if left unchecked, "put in jeopardy Earth's natural processes, our social fabric, and economic activity as a whole. This creates an arguably huge moral imperative for collective action" (Future-Fit Foundation, 2016: 13). They urge any company interested in long-term success to explore "proactively ... where its business model intersects with global challenges [to] find ways to enhance its resilience and competitiveness" (p. 13); otherwise, a business cannot really regard itself as truly "fit" for the "future." They maintain that their pragmatic approach can allow a company to reap three possible forms of payoff: increased company value, savings in costs, and reduced risks. In fact, cold-eyed investors are increasingly considering such long-term fitness factors in their securities evaluations (Unruh, Kiron, Kruschwitz, Reeves, Rubel, \& Meyer zum Felde, 2016).

The Benchmark lays out eight Future-Fit Business Principles to undergird business actions. Three of these, which pertain to the environment, prescribe that nature not be subjected to systematic increases in 1) "concentrations of substances extracted from the earth" (e.g., fossil fuel), 2) "concentrations of substances produced by society" (e.g., NOx, chlorofluorocarbons), or 3) ruin by physical means (e.g., degradation of soil, deforestation, over-fishing) (Future-Fit Foundation, 2016: 25). The other five principles relate to society and demand that business actions not subject people to obstacles in achieving health, influence, competence (e.g., education), impartiality (freedom from discrimination), and meaning-making (e.g., cultural expression).

\section{WHAT BUSINESSES CAN DO}

Other scholars have articulated this more ambitious level of behavior (e.g., Landrum \& Ohsowski, 2017) by describing a continuum of weak to strong sustainability. Weak sustainability places an economic value on natural resources and is open to compensating their depletion with economic ones. An example would be a developer that proposes to 
pay residents in exchange for despoiling their land; such a transaction would be deemed "fair." Strong sustainability, on the other hand, views natural resources as priceless and non-substitutable given their many direct and indirect benefits. An example would be clean water-reducing such can lead to deteriorating health and well-being for humans as well as diminished irrigation downstream. Maintaining adequate clean water supplies can permit enduring biodiversity, which prevents interruption of the food chain and continuously provides resources for pharmacological research.

Weak sustainability also supports the belief that continuous economic growth is necessary, bases decisions on cost-benefit analysis, and values progress as defined by increasing gross domestic product. In contrast, advocates for strong sustainability view growth as problematic and envision a future built around no growth. They prescribe that decisions be made based on their impact on the environment and welfare of living things (Landrum \& Ohsowski, 2017).

In light of this, Landrum and Ohsowski (2017) recently rated teaching materials and readings used in 51 American business schools of higher education. The results suggested gradations between the two poles of weak and strong sustainability, from compliance with regulations and competitive advantage all the way to systemic or regenerative change. However, over $50 \%$ of the readings used for undergraduates were classified under weak sustainability, with only $29 \%$ under strong sustainability. Indeed, this database allows educators to reflect on what sources they use and to consider other materials that can expose their students to more strong sustainability.

\section{FOUNDATIONAL LEARNING ABOUT MOVING TOWARD SUSTAINABILITY}

Our beginning survey course is called "Managing Sustainability in a Global Context." I open with readings that examine how to think about climate change, beginning with Greg Craven's What's the worst that could happen? A rational response to the climate change debate (2009). A high school science teacher, Craven skillfully offers a risk management approach to thinking about climate change. In a wry and engaging style, he invites readers to look at the decision about action on climate change as whether it's worth buying a kind of insurance policy-we are asked to think about the outcome if the world gears up for climate change that does not ensue as opposed to what disastrous results would occur if we do nothing but severe changes do occur. A useful section for undergrads 
also discusses how to understand scientific discovery and the role of peer review. It suggests a range of credibility that may be attributed to varied sources such as eminent scientists, advocacy-based think tanks, and talkradio commentators. The book also elaborates on common psychological limitations, such as the confirmation bias and limiting one's research to a single finding. Thus, while Craven's own leanings eventually come through, he leaves the reader to make his or her own decision on what action to take (if any) on climate change.

I also have students dip back into classics from the past. For example, reading the first few chapters of Rachel Carson's Silent spring (1962) (and viewing a recently released biography on Public Broadcasting System) exposes them to the early days of the environmental movement. Carson's writing, testimony in Congress, and advocacy work rank as one of the first whistleblowing campaigns, and students also learn how she endured vicious attacks from large chemical companies for reporting about the perils of DDT and other toxic pesticides. Indeed, her message about how pesticides linger in the soil and infect other growing plants (which in turn affect animals that eat them and then finally the humans who ingest those animals) offers a primer on the food chain and complex biological systems. Many students not schooled in the natural sciences can thus experience an epiphany with such systems learning.

In addition to the above, students also benefit from other exposures to ecological science. One such source is Sustainability: A comprehensive foundation (Theis \& Thomkin, 2015), a free PDF book in the public domain. It adds a more detailed scientific handling of climate change as well as a range of other topics. The compilation edited by Paul Hawken (2017) is also a recent addition to sources on climate change; it asserts that 100 of the most promising strategies for reducing carbon emissions or sequestering carbon can achieve "drawdown" of the world's greenhouse gases.

Another stirring reading comes from Jared Diamond's Collapse (2011). We read the chapter on the demise of early civilization on Easter Island. Students learn how the inhabitants, after surviving nicely for centuries by building wooden structures to live in and dug-out canoes for reaping generous harvests of fish at great distances, exhausted agricultural resources and devastated the forests over time, mostly to construct ritualistic structures as a show of strength against neighboring tribes elsewhere on the island. These actions rang the death knell for longdistance fishing and healthful nutrition, prompting vicious rivalries and eventually bloody tribal wars. The island's population thus shrank to an impoverished remnant, a far cry from the formerly prosperous nation. Such an accelerated decline over a relatively short period of time thereby 
offers a lesson in vicious cycles and a caution to us today about shortsighted, parochial behavior that can undermine the larger community.

Laasch and Conaway's Responsible business: The textbook for management learning, competence and innovation (2016) offers a useful treatment of concepts in how to think about and execute constructive actions for sustainability. Writing with the endorsement of the UN PRME office, the authors lay out the underlying conditions of the world and some conceptual underpinnings of sustainability. They expand upon what sustainable management practices would look like in the primary functions of logistics, operations, and customer relationship management (marketing, sales, and service). This includes debunking some of today's most "modern" practices that in fact undermine environmental goals. "Efficient" online purchasing and just-in-time shipping and delivery, for example, may save cost for the buyer but at the expense of excessive fossil fuel consumption for individualized transportation and packaging. The book also covers what responsible management can do in various support functions such as accounting, supply chain, and human resources.

Students can also glean information about sustainability issues from other parts of the world. They go on field trips whenever possible to visit a neighboring company or natural resource. Guest speakers from the sustainability field occasionally provide them with live stories of how firms are actually behaving. I encourage them to keep up with the New York Times, The Guardian, and other publications. We discuss convenient Internet sites, such as Smartbrief on Sustainability, CSR Wire, and Smartbiz.com. I may also require them to discuss in the classroom some current event about the environment, employment abuse, or world poverty.

I am convinced that undergraduate students, like most adults, often learn best and remember best by means of concrete examples. I therefore supplement their reading list with articles and chapters that demonstrate some of the things that specific businesses are currently doing to advance their greening efforts. For example, Alcatel-Lucent (now part of Nokia) has made great strides in its own operations and as a leader in industry alliances to design electronic systems that reduce energy consumption by an order of magnitude or more (Wirtenberg, 2014). Students also read about Unilever's dogged efforts to seek organic ingredients for food products (Gelles, 2015).

I have also allowed students to experience the temptation of overconsumption in the tragedy of the commons. Through an active exercise, they are invited to claim their share of a scarce resourceM\&M's in this case-without exceeding the supply (a bowl full of the 
chocolates). Alas, they invariably end up being too greedy, with the total of all claims being greater than the number of M\&M's available, thereby disqualifying everyone from eating any (unless the instructor relents after an in-depth debriefing).

Students also study the challenges companies face in taking responsibility for the behavior of their suppliers. One public shaming in this regard occurred in the aftermath of the many fatalities in the dreadful collapse of an apparel manufacturing building in Bangladesh in 2013. Evidence of brand names on garments found in the rubble pointed to American and European retailers as the outlets that seemed to be benefitting from blatantly irresponsible working conditions. One of them was Walmart, which turns out to have formerly contracted with a tenant in the ill-fated building but terminated the agreement months before due to concerns over dangerous and inhumane conditions. Walmart did not realize, however, that its new contractor proceeded to contract with the original firm to continue making products in the same decrepit building. As such, this serves as just one instance of students learning some of the dilemmas and unintended consequences of efforts to improve sustainability.

I estimate that most of the readings I assign are under the category of weak sustainability. Only occasionally do I expose students to some strong sustainability. I feel rather comfortable with this overall emphasis, though, as most students enter this foundational class with a low level of awareness about the subject. It thus seems somewhat necessary to enlighten them about fundamental principles of sustainability before they can thoughtfully contemplate what strong sustainability could look like. Indeed, while this would not apply to our students in MBA and Executive MBA classes, I think these undergraduates need to acquire a nuanced understanding of such issues and a mature worldview and mindset to appreciate the audacious aims of full-blown strong sustainability. I thereby hope that I can, over time, move our emphasis in a stronger direction.

\section{ENGENDERING A SUSTAINABILITY WORLDVIEW}

I maintain that eliciting and developing a sustainability mindset in students is a powerful result for an educator. As Senge et al. (2008) said, "All real change is grounded in new ways of thinking and perceiving" (p. 10). Change needs to be rooted in one's deep conception of self and relationship with others, community, and the world. 
Psychologist Steve Schein identifies "worldview" as a necessary component for someone to deal seriously with issues and behavior concerning sustainability. Having interviewed 75 corporate executives working in the field, he learned about the origins of their concerns for the natural world (Schein, 2015a, 2015b); reasons included early life experiences, such as family of origin, teachers, and seeing poverty and natural degradation, as well as a sense of spirituality and service. Many respondents also reported their awareness of being embedded in the natural ecology, the vulnerability of the earth, and the value of nature. Worldviews may thus be seen through the lens of moral and ego development; Brown (2012, cited in Schein, 2015a: 99) asserts that they become "more complex and encompassing" over time. They may be classified as "pre-conventional" (related to the impulsive and opportunistic), "conventional" (in tune with social conventions and short-term economic goals), or "post-conventional" (greater appreciation for the reframing of complex issues, interdependence of systems, and awareness of long-term implications of sustainability).

While Schein relates this typology of worldviews to the executives in his study, it may be equally applied to students. Most undergraduates would fit the pre-conventional category, but some may be able to begin moving into the conventional and post-conventional with the help of powerful educational techniques and experiences.

Bob Doppelt (2012) provides another insight into the worldview needed to bring about sustainability. He describes this change of worldview as converting one's primary focus "from Me to We." To do so means the ability to make five "commitments":

1. See the systems you are a part of. This commitment focuses our attention on how we are integrated into a larger whole (Ackoff, 2015; Ackoff, Addison, \& Bibb, 2007). One system is nested inside another, and more and more ecosystems make up the entire biosphere.

2. Be accountable for all the consequences of your actions. With an imperfect understanding of systems dynamics and various cognitive and self-serving biases, we instinctively focus on symptoms, single causes, and near-term, oneway causation rather than on feedback loops and nonlinear change (Mazutis \& Eckardt, 2017).

3. Abide by society's most deeply held universal principles of morality and justice. Today's death, disruption, and displacement due to climate change fly in the face of 
espousing justice for all. Other cultures and regions of the world invisible to most westerners, notably the poorest and sickest on the planet, also deserve the same level of justice as the most affluent.

4. Acknowledge your trustee obligations and take responsibility for the continuation of all life. Doppelt suggests thinking about the earth as a "living trust" whereby "trustees" in the present have the responsibility to use the subject assets not for personal gain but to monitor their condition in view of passing them on to future beneficiaries. In ecological terms, this means managing the earth in a sustainable fashion, not engaging in profligacy or economic growth that depletes assets.

5. Choose your own destiny. We easily become resigned to the current state of affairs. Reinforcing this tendency may be the "confirmation bias" that insidiously leads us to filter out information that conflicts with our existing beliefs and embrace inputs that support them (Haidt, 2012; Kahneman, 2011; Marshall, 2015).

Rising to each of these commitments requires a substantial change in consciousness and actions to absorb fully their worldview. As many scholars of behavior change note, changing deeply rooted behavior requires more than simply reframing one's thoughts and beliefs (Hoffman, 2016; Rimanoczy, 2013).

\section{THE CHALLENGE OF MOVING FROM SUSTAINABILITY WORLDVIEW TO SUSTAINABILITY MINDSET}

Absorbing a sustainability worldview is a necessary condition for major change in individuals and groups. In light of this, many scholars advance the notion of cognitions (Mazutis \& Eckardt, 2017). Profound change in an individual, however, requires consideration of the whole person. One's "mindset" embraces more than the thoughts and beliefs of a worldview, and includes one's sense of identity, emotions, and cognitive processes that originate in the more non-linear and creative right hemisphere of the brain.

A more comprehensive treatment of mindset comes from the work of Isabel Rimanoczy (2013). She has written and taught about what it means to produce a sustainability mindset and serves as chair of the 
Sustainability Mindset Working Group under the UN PRME. Through qualitative research involving sixteen sustainability leaders, she factored out two dimensions that account for their dedication to sustainability: 1) Personal Mission and 2) Social Sensitivity. Regarding the first, all her interviewees reported the centrality of a sense of mission, purpose, and values that grounds their activities. They relate a deep sense of calling to this work (cf. Hoffman, 2016), often involving a spiritual dimension even though such language is not always welcome in the workplace. As a result, taking early action in sustainability often deepened their sense of mission, which in turn kindled a more compelling drive for that mission as well as vigorous action in a virtuous cycle. Rimanoczy thus posits that a sustainability mindset results from the interaction among three elements: "Knowing," or the cognitive dimension; "Doing," or actions; and "Being," which embraces one's identity, emotions, and right-brain awareness. One of Rimanoczy's subjects, for instance, reported that after getting immersed in sustainability work-the Doing-it became something that "I had to do," illustrating the importance of feelings as a key component of mindset and which complement Knowing and Doing. Rimanoczy applies this triad to what she recommends for educating toward a sustainability mindset.

The second dimension shared by interview subjects was an intense social sensitivity to the world's poverty, inequity, and suffering. Feelings of anger, pain, or even of despair or depression often grew out of events in their own lives or in the lives of those close to them, leading them to bold action. In other words, human impact was especially motivating to them, more so than mere abstractions of global problems. For these individuals, the sensitivity was long-lasting as opposed to, for example, the sensitivity behind the surge of intervention immediately following a natural disaster.

To achieve a sustainability mindset, Rimanoczy (2013), drawing on earlier work by John Adams (2000, 2008), maintains that people must transform both their thinking and their way of being on several dimensions. Three of these are:

1. time orientation-from short-term to long-term;

2. scope of attention-from local to global; and

3. prevailing logic - from either/or to both/and.

Doppelt's five commitments incorporate these dimensions as well, and they may be seen within a continuum where most of us use the thinking at the left end. Other aspects of systems thinking which we may include here are interdependence, cyclical flow, complexity, and cooperation through partnerships. Incorporating this kind of thinking, 
however, and moving to the far right of the continuum where such thought and action can steer how we deal with sustainability issues, requires increased self-awareness and disciplined intent.

Rimanoczy, however, goes beyond Doppelt (and, in many ways, Schein) in asserting the necessity of transforming one's way of "being" in different respects to achieve a true sustainability mindset. She touches on three more dimensions:

4. focus of response-from reactive to creative;

5. problem or error consideration-from accountability and blame to learning; and

6. life orientation-from doing and having to being.

Reflective corporate leaders know that they themselves must be aware of their own sense of meaning - "the feeling individuals have about the fundamental meaning of who they are, what they are doing, [and] the contributions they are making" (Vaill, 1998: 219) —and encourage the same in their associates (Bolman \& Deal, 2011; Moore, 1995; Neal, 2013).

Why, then, is there so little action to reverse course? After all, the deterioration of the globe has received increased attention in recent years, and many people consider themselves sympathetic to the idea of slowing the decline. Rimanoczy points to several factors in the resistance to change:

- Economic growth. The increase in wealth in the developed world has firmly accustomed us to the payoffs of growth despite the accompanying increase in pollution, climate change, income inequality, and accelerating decline in natural resources. Commentators like John Ehrenfeld (Ehrenfeld \& Hoffman, 2013), Bill McKibben (2011), and Riane Eisler (2008) are among the relatively few voices who dare to challenge the conventional wisdom that growth is the sole source of satisfaction rather than an approach based on more prudence, caring, and spiritual richness.

- Achievement. Western society has achievement embedded in almost all forms of life, whether it concerns personal wealth, luxury consumption, athletics, or social status.

- Control. Humans have claimed their superiority over the animal world for centuries, and this carries over to controlling the earth itself. It manifests in the pursuit of 
unlimited fishing, mining, oil extraction, dumping of effluents into fresh water, and spreading fertilizers into the soil. Such "species arrogance" has led to the extinction of massive amounts of biodiversity (Kolbert, 2015).

- Wealth. Some trace the drive for wealth to the $19^{\text {th }}$ century Industrial Revolution, which was predicated on the belief that seeking private wealth is a primary motivator and even a virtue in itself. For most people today, economic freedom is the basis for all freedom. Such motivation can be powerful even while it leads to destructive feelings of entitlement, envy, guilt, or resentment for many.

- Comfort. While not intrinsically wrong, much of the quest for comfort in modern society has been carried out at the expense of natural resources that have been exploited beyond any sustainable level.

- Independence. Cultures vary along these lines. Nevertheless, the general tendency of Americans toward a more individualistic construal of self, as compared to more collectivistic orientations, militates against easily acquiring a mindset concerned with global welfare (Markus \& Kitayama, 1991).

- Competition. As mentioned above, the drive to compete runs deep. "Survival of the fittest," however, reveals linear thinking and leaves little room for notions of collaboration for the common good. Hardcore market values and competition thus crowd out compassion and care for others and the world.

- Knowledge. While admired as a true resource, knowledge can flood our consciousness and crowd out the holistic awareness and real wisdom needed to comprehend our complex universe.

- Speed. Like the fire hose of knowledge that bombards us, the norm of speed offers the illusion of high productivity, even though it can leave little room for multi-faceted consideration and profound reflection. Both these two are needed to deal with sustainability.

What exactly can we do, then, to hold on to our aspirations for true sustainability and get beyond the shackles of the resistance factors? 
Rimanoczy suggests three general ways. One is to redefine our values and reshape them in a fundamentally more useful manner. For example, the value of growth and personal wealth may shrink if reframed with the questions, "Growth and wealth for what? For whom?" If we form an answer while considering a world that is depleting its resources and depriving three billion people of basic nutrition, health, and stable family life, our own wealth starts to seem like a superficial, self-centered goal. If we can detach ourselves from an identity shaped by our possessions and social status, we can tune in to a hole in our heart that could lead to us sharply curtailing our consumption, our living space, and the "things" needed for true fulfillment (Smith, 2017). In addition to this, a more neutral or even positive dose of media could also eventually support us in changing our spirit and expectations. Today's media strongly affect what we perceive and what we expect-when the TV news reports vicious political back-biting, mayhem, and crime on a daily basis, for example, it builds expectations of a self-centered, fear-drenched life in the world.

A second avenue toward getting beyond resistance concerns globalization and social media. Regrettably, these have often accelerated unsustainable practices around the world, such as exporting Western values around diet, competition, and materialism. Consider sharp increases in the number of diabetes cases in India, for example, as the burgeoning middle class gravitates toward rich American foods and the obesity that results from them (Kleinfield, 2006). Nevertheless, examples of social media that bring out an extraordinary kind of collaboration for world benefit do exist, such as www.One.org founded by Bono or www.Change.org, both of which rally grassroots advocacy for worthy causes (see also Kristof \& WuDunn, 2015). Expanding awareness of such networks, therefore, can inspire others to multiply participation around the world.

The third way that Rimanoczy suggests for getting beyond factors that discourage sustainable behavior is to depart from the classical scientific approach of left-brain analysis (of sustainability) and cultivate the capabilities of the brain's right hemisphere. The left brain propagates the idea of being in control with either/or logic as opposed to utilizing our abilities to detect holistic patterns and creative ambiguity. The right brain, on the other hand, is better able to appreciate the wisdom of our ancestors. Rimanoczy thus urges us to consider the virtues of early scientists who generated deep insights through strong intuition, insights which may be quashed today by the premium put on positivistic proof. She quotes Thoreau, who wrote, "I must walk with more free sense ... I must let my senses wander as my thoughts, my eyes see without looking.... The more you look the less you will observe.... What I need is not to look at all, but a true sauntering of the eye" (Rimanoczy, 2013: 157, emphasis added). 
With little neurological knowledge, Thoreau was describing the whole person as the best way to explore and learn.

Another source of hope arises from the possibility for our minds to evolve. This can include gradually moving beyond the illusion of independence and achievement. Just being open to slowing down in our speed-obsessed culture, for instance, can introduce us into a pace of existence that affords the chance to heighten our self-awareness. Aesthetic and artistic experiences can amplify greater mindfulness and identification of life's purpose (Yang, in press). This guides us to engage better with problem-solving in the presence of complexity and ambiguity.

\section{DEVELOPMENT OF AN IN-DEPTH SUSTAINABILITY MINDSET: KNOWING, DOING, AND BEING}

Educating our students to grow into a sustainability mindset is a demanding mission. Much of the transition may take a lifetime to achieve, if ever. It is imperative that students acquire a basic understanding of ecoliteracy, climate change, other threats to the world, and of approaches that companies are seeking to undertake. Many of the activities described above, therefore, relate to traditional methods of conveying knowledge. Yet advocates of experiential education have long stressed the need for students to get hands-on learning - the Doing-which can be much more enduring and meaningful (e.g., Kolb, 2014). Moreover, as learners of all ages are facing the need to transform their behavior and long-held beliefs about nature and humanity, they can also benefit deeply from shifting their Being.

Table 2 compiles an array of possible activities that offer learning in all three dimensions. The most non-traditional relate to Doing and Being. At Fairleigh Dickinson University, for instance, students begin their sustainability journey through service-learning. Everyone majoring in Management conducts at least one community service project for the benefit of some group or NGO; some actual examples of these include fundraising for schools in rural Cambodia, underwriting wells in Ethiopia and Haiti, and exposing the campus to knowledge about the genocide in Darfur. Consequently, those involved in these projects consistently report a deepening sense of compassion for the beneficiaries while sharpening their cognitive and management skills. Some courses also require students to interview a social entrepreneur about business that is set up to make money but also to serve the broader world. The analyses of their learnings are then submitted to the nonprofit Aim2Flourish (www. aim2flourish.org), which adds the inspiring stories to its open global 
library. Students can also on occasion listen to talks given by speakers as arranged by our institute, speakers who are devoted to sustainability, innovation, and entrepreneurship. Their topics include provocative subjects involving corporate actions and discussions about their valuesbased philosophy as well as best practices in their strategies. Finally, the university's required freshman core course has also incorporated a module on sustainability. Indeed, such experiences provoke knowledge and inspiration for students' own future actions. Over time, all our students will at least know some of the vocabulary and key concerns surrounding sustainability.

\begin{tabular}{|c|c|c|c|c|}
\hline $\begin{array}{l}\text { Desired } \\
\text { Learning }\end{array}$ & Activity & Know & Do & $B e$ \\
\hline \multirow{4}{*}{ Eco-literacy } & $\begin{array}{l}\text { T. Theis \& J. Thomkin (eds.)., Sustainability: } \\
\text { A comprehensive foundation }\end{array}$ & $\mathrm{X}$ & & \\
\hline & R. Carson, Silent spring (excerpts) & $\mathrm{X}$ & & \\
\hline & Module on fresh water & $\mathrm{X}$ & & \\
\hline & Video on the state of the planet & $\mathrm{X}$ & & \\
\hline \multirow{4}{*}{$\begin{array}{l}\text { Climate } \\
\text { Change }\end{array}$} & G. Craven, What's the worst that could happen? & $\mathrm{X}$ & & \\
\hline & P. Hawken (ed.)., Drawdown (excerpts) & $\mathrm{X}$ & & \\
\hline & $\begin{array}{l}\text { T. Theis \& J. Thomkin (eds.)., Sustainability: A } \\
\text { comprehensive foundation }\end{array}$ & $\mathrm{X}$ & & \\
\hline & $\begin{array}{l}\text { J. Hansen, "Why I Must Speak Out About } \\
\text { Climate Change," TED }\end{array}$ & $\mathrm{X}$ & & \\
\hline \multirow{2}{*}{$\begin{array}{l}\text { Other Global } \\
\text { Threats }\end{array}$} & J. Diamond, "Easter Island," in his Collapse & $\mathrm{X}$ & & \\
\hline & Tragedy of the Commons-Exercise with M\&M's & $\mathrm{X}$ & $\mathrm{X}$ & \\
\hline \multirow{3}{*}{$\begin{array}{c}\text { Corporate } \\
\text { Approaches \& } \\
\text { Stories }\end{array}$} & $\begin{array}{l}\text { Future-Fit Foundation, Future-fit business } \\
\text { benchmark }\end{array}$ & $\mathrm{X}$ & & \\
\hline & Laasch \& Conaway, Responsible business & $\mathrm{X}$ & & \\
\hline & $\begin{array}{l}\text { Press accounts on Wal-Mart, Unilever, } \\
\text { Patagonia, Alcatel-Lucent, etc. }\end{array}$ & $\mathrm{X}$ & & \\
\hline \multirow{3}{*}{$\begin{array}{l}\text { World } \\
\text { Economy }\end{array}$} & $\begin{array}{l}\text { Tim Kasser, "The high price of materialism," } \\
\text { The Center for New American Dream (2011). } \\
\text { Available at https://www.youtube.com/ } \\
\text { watch?v=oGab38pKscw }\end{array}$ & $\mathrm{X}$ & & \\
\hline & $\begin{array}{l}\text { Annie Leonard, "Story of stuff," Tides } \\
\text { Foundation, Funders Workgroup for Sustainable } \\
\text { Production and Consumption, and Free Range } \\
\text { Studios (2009). Available at https://www. } \\
\text { youtube.com/watch?v=9GorqroigqM }\end{array}$ & $\mathrm{X}$ & & \\
\hline & R. Eisler, The real wealth of nations & $\mathrm{X}$ & & \\
\hline
\end{tabular}




\begin{tabular}{|c|c|c|c|c|}
\hline $\begin{array}{l}\text { Desired } \\
\text { Learning }\end{array}$ & Activity & Know & Do & $\mathrm{Be}$ \\
\hline \multirow{3}{*}{$\begin{array}{l}\text { Corporate } \\
\text { Actions }\end{array}$} & Guest speakers & $\mathrm{X}$ & & \\
\hline & Field trips & $\mathrm{X}$ & $\mathrm{X}$ & \\
\hline & On-campus speakers & $\mathrm{X}$ & & \\
\hline \multirow{3}{*}{$\begin{array}{l}\text { On-campus } \\
\text { Projects }\end{array}$} & Clean-up of river and grounds & & $\mathrm{X}$ & $\mathrm{X}$ \\
\hline & Planting garden of vegetables, etc. & & $\mathrm{X}$ & $\mathrm{X}$ \\
\hline & Campus Green Club & $\mathrm{X}$ & $\mathrm{X}$ & $\mathrm{X}$ \\
\hline \multirow{2}{*}{$\begin{array}{l}\text { Consider } \\
\text { Personal } \\
\text { Behavior }\end{array}$} & Compute personal carbon footprint & & $\mathrm{X}$ & $\mathrm{X}$ \\
\hline & $\begin{array}{l}\text { S. Shulman, et al., Cooler smarter: Practical } \\
\text { steps for low-carbon living }\end{array}$ & & $\mathrm{X}$ & $\mathrm{X}$ \\
\hline \multirow{3}{*}{$\begin{array}{l}\text { Understand } \\
\text { Social Entre- } \\
\text { preneurship }\end{array}$} & $\begin{array}{l}\text { Interview social entrepreneurs \& submit } \\
\text { results to Aim2Flourish.com }\end{array}$ & $\mathrm{X}$ & $\mathrm{X}$ & $\mathrm{X}$ \\
\hline & Attend talks on campus & $\mathrm{X}$ & $\mathrm{X}$ & \\
\hline & Campus chapter of Enactus & $\mathrm{X}$ & $\mathrm{X}$ & \\
\hline \multirow{3}{*}{$\begin{array}{c}\text { Global } \\
\text { Awareness }\end{array}$} & Study UN Sustainable Development Goals & $\mathrm{X}$ & & \\
\hline & Do service-learning projects & $\mathrm{X}$ & $\mathrm{X}$ & $\mathrm{X}$ \\
\hline & Study abroad & $\mathrm{X}$ & $\mathrm{X}$ & $\mathrm{X}$ \\
\hline \multirow{2}{*}{$\begin{array}{c}\text { Self- } \\
\text { Awareness }\end{array}$} & Journaling & & $\mathrm{X}$ & $\mathrm{X}$ \\
\hline & Meditation & & $\mathrm{X}$ & $\mathrm{X}$ \\
\hline \multirow{3}{*}{$\begin{array}{c}\text { Identify } \\
\text { Personal } \\
\text { Purpose and } \\
\text { Mission }\end{array}$} & $\begin{array}{l}\text { Write about "Receiving Amazing } \\
\text { Achievement Award" }\end{array}$ & & $\mathrm{X}$ & $\mathrm{X}$ \\
\hline & Write about "My Legacy" & & $\mathrm{X}$ & $\mathrm{X}$ \\
\hline & Write about "My Identity" & & $\mathrm{X}$ & $\mathrm{X}$ \\
\hline $\begin{array}{l}\text { Relationship } \\
\text { with } \\
\text { Sustainability }\end{array}$ & Write about "My View on Sustainability" & & $\mathrm{X}$ & $\mathrm{X}$ \\
\hline
\end{tabular}

Table 2: Assigned Activities

Schein (2015a) points to the impact on his students-and on himself-in learning more systems thinking at a deep level when he immersed himself in "permaculture" near campus, a combination of how Doing can deepen one's Knowing and Being. He also recommends greater exposure to eco-science for students, along with deep reflection and journaling. Such an effort to infuse "ecological literacy" was embodied in similar fashion by a two-decade long multi-dimensional program at Ramapo College of New Jersey (Edelstein, 2009).

Another simple exercise from Rimanoczy is to have students walk silently through nature for sixty minutes without any electronics, cameras, or papers, and then write about the experience afterward in 
their journals. The benefit of this kind of Doing is to have a potentially profound effect on one's Being. The outcome is similar for an NGO that does outdoor education for young people; their mission statement refers to using the "earth as educator" (Trekkers, 2017).

A further cue can be taken from researcher and consultant Philip Mirvis who has led senior executives on field trips to impoverished third world countries. Participants increased their self-awareness and understanding of others by visiting remote parts of the globe. They also reported a powerful executive development experience while engaging with the least fortunate inhabitants on earth (Mirvis, 2008). Indeed, such experiences have since helped these executives connect global issues to areas pertinent to their companies. On that note, a similar kind of experiential learning can have real impact on college students as well, such as what happened with those who studied sustainability on our university's trips to Costa Rica. Furthermore, some of our other students are able to study abroad and gain exposure to different worldviews (even if most of them go to developed countries). Nevertheless, studying at home next to foreign schoolmates can also offer another version of this broadening of perspective, albeit in a familiar context.

\section{CONCLUSION}

We have not yet incorporated all these activities and knitted them into an integrated whole. The results I would like to see require a longterm and complex process for educating our undergraduates. Through such a process, however, many of our school's alumni may be able to influence the sustainability actions of their future employers. Some may even work full-time in this domain. In any case, we can be proud over time that we enabled them to examine their Being and deep identity in preparation for a rewarding, purpose-driven career and life.

Based on our results to date, and the gaps that are visible, several elements of this worthy goal stand out. I thereby suggest that instructors should aspire to guide students toward capabilities such as these:

- understanding some of the science of environment and ecology;

- comprehending complex systems and systems thinking;

- feeling part of a larger world;

- possessing the confidence to think long-term and far beyond their comfortable horizons; 
- acquiring a mindset to go beyond "Me" to "We" while considering their legacy as it will affect their descendants as well as the abject poor and endangered today; and

- beginning to ascertain the kind of behavior they wish to exhibit in their personal and professional lives to contribute to a world worth leaving behind.

This article has thus reported on a way of raising awareness about sustainability issues and objectives that need to be accomplished according to the United Nations' Sustainable Development Goals and the principles of Future-Fit. "Flourishing" indeed stands as an ambitious goal. It also describes some of what students learn that businesses are already doing as well as the challenge of "strong sustainability." I myself take many steps to enable students to go beyond foundation principles and begin to acquire a sustainability worldview. More in-depth results are needed, along with ideas and activities that produce some of the sustainability mindset that is essential for powerful actions in the future.

For business schools to fulfill their mission, therefore, it is imperative to incorporate sustainability into the curriculum and the overall experience. This multi-faceted effort requires creativity, rigor, and patience-we ourselves have begun the journey at our university but we have an enormous amount of work ahead of us before we have broad impact. Guidance from the United Nations' Sustainable Development Goals, other colleagues enrolled in PRME, and other scholars can help us considerably in this regard. As with any accomplishment of real merit, we need to persist vigorously toward this crucial goal for the good of the world.

\section{REFERENCES}

Ackoff, R. 2015. Systems thinking speech by Dr. Russell Ackoff. YouTube. Available at https://youtu.be/EbLh7rZ3rhU?t=1.

Ackoff, R. L., Addison, H. J., \& Bibb, S. 2007. Management f-laws: How organizations really work. London: Triarchy Press Ltd.

Adams, J. D. 2000. Thinking today as if tomorrow mattered: The rise of a sustainable consciousness. San Francisco: Eartheart Enterprises.

Adams, J. D. 2008. Six dimensions of mental models. In J. Wirtenberg, W. G. Russell, D. Lipsky, Amacom, \& Enterprise Sustainability Action Team (Eds.), The sustainable enterprise fieldbook: When it all comes together: 60-70. Sheffield, UK: Greenleaf.

Barbier, E. 1987. The concept of sustainable economic development. Environmental Conservation, 14(2): 101-110. 
Bolman, L. G., \& Deal, T. E. 2011. Leading with soul: An uncommon journey of spirit (rev. 3rd ed.). San Francisco: Jossey-Bass.

Brown, B. C. 2012. Conscious leadership for sustainability: How leaders with a late-stage action logic design and engage in sustainability initiatives. Doctoral dissertation, Fielding Graduate University, California. Cited in Schein, S. (2015a). Carson, R. 1962. Silent spring. New York: Houghton Mifflin.

Craven, G. 2009. What's the worst that could happen? A rational response to the climate change debate. New York: Penguin.

Diamond, J. 2011. Collapse: How societies choose to fail or succeed (rev. ed.). New York: Penguin Books.

Doppelt, B. 2012. From me to we: The five transformational commitments required to rescue the planet, your organization, and your life. Sheffield, UK: Greenleaf. Edelstein, M. 2009. Ecological literacy in the undergraduate curriculum: Ramapo College of New Jersey's pioneer sustainability curricular infusion project. The Place for Sustainability in Higher Education Special Issue: Thresholds in Education, 35(1-2):, 23-31.

Ehrenfeld, J. R. 2009. Flourishing forever: An interview with John R. Ehrenfeld. MIT Sloan Management Review, Reprint No. 51120.

Ehrenfeld, J. R., \& Hoffman, A. J. 2013. Flourishing: A frank conversation about sustainability. Stanford, CA: Stanford University Press.

Eisler, R. T. 2008. The real wealth of nations: Creating a caring economics. San Francisco: Berrett-Koehler.

Elkington, J. 1998. Cannibals with forks: The triple bottom line of 21st century business. Gabriola Island, Canada: New Society Publishers.

Future-Fit Foundation. 2016. Future-fit business benchmark, part 1: Concepts, principles and goals. Release 1. Available at http://futurefitbusiness.org/wpcontent/uploads/2015/05/Future-Fit-Business-Benchmark-Part-1-ConceptsPrinciples-and-Goals-R1.pdf.

Gelles, D. 2015. Unilever finds that shrinking its footprint is a giant task. The New York Times, Nov. 21. Available at http://www.nytimes.com/2015/11/22/business/ unilever-finds-that-shrinking-its-footprint-is-a-giant-task.html (accessed March 15, 2017).

Haidt, J. 2012. The righteous mind: Why good people are divided by politics and religion. New York: Vintage Books.

Hansen, J. 2012. Why I must speak out about climate change. TED. Available at https://youtu.be/fWInyaMWBY8.

Hawken, P. (Ed.). 2017. Drawdown: The most comprehensive plan ever proposed to reverse global warming. New York: Penguin.

Hoffman, A. J. 2016. Finding purpose: Environmental stewardship as a personal calling. Abington, UK: Greenleaf Publishing Ltd.

Kahneman, D. 2011. Thinking, fast and slow. New York: Farrar, Straus, and Giroux. Kleinfield, N. R. 2006. Modern ways open India's doors to diabetes. New York Times, September 13. Available at http://www.nytimes.com/2006/09/13/world/ asia/13diabetes.html (accessed August 15, 2017). 
Kolb, D. A. 2014. Experiential learning: Experience as the source of learning and development (2nd ed.). Upper Saddle River, NJ: Pearson.

Kolbert, E. 2015. The sixth extinction: An unnatural history. New York: Picador.

Kristof, N., \& WuDunn, S. 2015. A path appears: Transforming lives, creating opportunity. New York: Vintage.

Laasch, O., \& Conaway, R. 2016. Responsible business: The textbook for management learning, competence and innovation. Saltaire, UK: Greenleaf.

Landrum, N. E., \& Ohsowski, B. 2017. Content trends in sustainable business education: An analysis of introductory courses in the USA. International Journal of Sustainability in Higher Education, 18(3): 385-414.

Laszlo, C., \& Brown, J. S. 2014. Flourishing: The new spirit of business enterprise. Stanford, CA: Stanford University Press.

Markus, H. R., \& Kitayama, S. 1991. Culture and the self: Implications for cognition, emotion, and motivation. Psychological Review, 98(2): 224-253.

Marshall, G. 2015. Don't even think about it: Why our brains are wired to ignore climate change. New York: Bloomsbury.

Mazutis, D., \& Eckardt, A. 2017. Sleepwalking into catastrophe: Cognitive biases and corporate climate change inertia. California Management Review, 59(3): 74-108.

McKibben, B. 2011. Eaarth: Making a life on a tough new planet. New York: St. Martin's Griffin.

Mirvis, P. 2008. Executive development through consciousness-raising experiences. Academy of Management Learning \& Education, 7(2): 173-188.

Moore, T. 1995. Care of the soul: A guide for cultivating depth and sacredness in everyday life. New York: Harper.

Neal, J. 2013. Creating enlightened organizations: Four gateways to spirit at work. New York: Springer.

Rimanoczy, I. 2013. Big bang being: Developing the sustainability mindset. Sheffield, UK: Greenleaf.

Schein, S. 2015a. A new psychology for sustainability leadership: The hidden power of ecological worldviews. Sheffield, UK: Greenleaf.

Schein, S. 2015b. Ecological worldviews: A missing perspective to advance global sustainability leadership. Journal of Management for Global Sustainability, 3(1): 1-24.

Senge, P., Smith, B., Kruschwitz, N., Laur, J., \& Schley, S. 2008. The necessary revolution: How individuals and organizations are working together to create a sustainable world. New York: Doubleday.

Shulman, S., Deyette, J., Ekwurzel, B., Friedman, D., Mellon, M., Rogers, J., \& Shaw, S. 2012. Cooler smarter: Practical steps for low-carbon living. Washington, DC: Union of Concerned Scientists / Island Press.

Smith, E. E. 2017. The power of meaning: Finding fulfillment in a world obsessed with happiness. New York: Broadway Books.

Theis, T., \& Thomkin, J. (Eds.). 2015. Sustainability: A comprehensive foundation. OpenStax CNX. Houston: Connexions. Available at https://cnx.org/ contents/1741effd-9cda-4b2b-a91e-003e6f587263@43.5. 
Trekkers. 2017. Trekkers' mission. Available at http://trekkers.org/mission/ (accessed July 3, 2017).

United Nations. 2017. Sustainable development goals. Available at http://www. un.org/sustainabledevelopment/sustainable-development-goals/ (accessed November 21, 2017).

Unruh, G., Kiron, D., Kruschwitz, N., Reeves, M., Rubel, H., \& Meyer zum Felde, A. 2016. Investing for a sustainable future: Investors care more about sustainability than many executives believe. MIT Sloan Review, 57(4): 1-32.

Vaill, P. 1998. Spirited leading and learning: Process wisdom for a new age. San Francisco: Jossey-Bass.

Wirtenberg, J. 2014. Building a culture for sustainability: People, planet, and profits in a new green economy. New York: Praeger.

Yang, C. (in press). Making sense of mindfulness in management education. In I. Rimanoczy \& K. Kassel (Eds.), Sustainability mindset development in management. Yorkshire, England: Greenleaf.

Kent D. Fairfield is Associate Professor of Management at the Silberman College of Business, Fairleigh Dickinson University. He teaches leadership, personal development, and team effectiveness, as well as sustainability management. His research concerns individual and organizational factors underlying sustainability management and improved pedagogy. 